\title{
VORWORT DES AUTORS \\ ZUR DEUTSCHEN AUSGABE
}

Ich freue mich, daß der bekannte und angesehene Akademie-Verlag es für zweckmäßig hielt, die Leser der Deutschen Demokratischen Republik mit meinem Buch über die Morphologie von Daten bekanntzumachen.

Die Zeit von fünf Jahren seit der Orginalbearbeitung des Textes hat mich in der Uberzeugung bestärkt, da $\beta$ dieser hervorgehobene Aspekt der Informatik ein begründetes Recht auf thematische Selbständigkeit besitzt. Ein besonders wesentliches Argument, das für die Richtigkeit dieses Standpunktes spricht, ist eine sehr intensive Entwicklung von Arbeiten auf dem Gebiet sogenannter Datenbanken, die in der Praxis eine breite Anwendung finden.

Als Verfasser, der die deutsche Sprache nicht in dem Grade beherrscht, um die Ubersetzung zu autorisieren, bin ich den Bearbeitern dieses Buches, Herrn Prof. H. Thiele und Herrn G. Paulin, zu aufrichtigem Dank verpflichtet für die Mühe, den Text mit der in der DDR üblichen Terminologie und den Gepflogenheiten der Verlagsreihe in Ubereinstimmung zu bringen sowie für die Ergänzung des Literaturverzeichnisses mit Arbeiten, die den Lesern der DDR leichter zugänglich sind.

Prof. Dr. hab. Wladyslaw M. TuRski 
